18

\title{
Optimization of Excitation and Detection Modes to Detect Ultra-Small Amounts of Semiconductor Quantum Dots Based on Cadmium Selenide
}

(C) Y.A. Kuzishchin ${ }^{1}$, I.L. Martynov ${ }^{1}$, E.V. Osipov ${ }^{1}$, P.S. Samokhvalov ${ }^{1}$, A.A. Chistyakov ${ }^{1}$, and I.R. Nabiev ${ }^{1,2}$

${ }^{1}$ National Research Nuclear University MEPhl,

115409, Moscow, Russia

${ }^{2}$ University of Reims Champagne-Ardenne,

51100, Reims, France

e-mail: yriy.kuzishchin@gmail.com

Received July 6, 2018

At present, fluorescent spectroscopy is a powerful tool that is used in many biology applications. In practice, fluorescent labels based on organic dyes and semiconductor quantum dots are used. It is noteworthy that the semiconductor quantum dots have distinct advantages over organic dyes. At the same time, the efficiency parameters and modes of detection and excitation have not been investigated sufficiently. The results of theoretical study on the optimization of the excitation and detections modes for detecting ultra-small amounts of $\mathrm{CdSe} / \mathrm{ZnS}$ core/shell semiconductor quantum dots are presented at this paper.

DOI: $10.21883 /$ OS.2018.11.46840.217-18

\footnotetext{
* International Conference „PCNSPA 2018 - Photonic Colloidal Nanostructures: Synthesis, Properties, and Applications", Saint Petersburg, Russia, June 4-8, 2018.

Полный текст статьи опубликован в английской версии журнала.
} 